\title{
Comparing HMG-CoA Reductase Inhibitors
}

\author{
Peter H. Jones, M.D. \\ Baylor College of Medicine, Houston, Texas, USA
}

\begin{abstract}
Summary: The statins have proved to be some of the most potent therapies for reducing elevated low-density lipoprotein (LDL) cholesterol and lessening the risk of coronary heart disease (CHD) and related events. Nonetheless, there are still questions about the clinical relevance of individual drug characteristics, such as chemical derivation, solubility properties, and metabolic route, in terms of tolerability or therapeutic benefit. At the same time, no clear explanation has emerged for the significantly steeper reductions in LDL cholesterol levels achieved with atorvastatin versus lovastatin, simvastatin, pravastatin, or fluvastatin, or, more recently, with rosuvastatin versus atorvastatin, although possible mechanisms have been suggested. More studies are needed to characterize the effects of statins on high-density lipoprotein (HDL) in different patient groups. Clearly, though, several statins have yielded significant reductions in CHD risk and have shown to be well tolerated in both primary and secondary prevention trials. The possibility that statins exert pronounced effects beyond lowering blood lipids is opening other avenues of research into the benefits of these drugs.
\end{abstract}

Key words: coronary heart disease, dyslipidemia, statins

\section{Introduction}

A large body of evidence demonstrates that reducing the levels of low-density lipoprotein (LDL) cholesterol lessens the risk of coronary heart disease (CHD) and related events. ${ }^{1}$ The 3-hydroxy-3-methylglutaryl coenzyme A (HMG-CoA) reductase inhibitors (statins) lower LDL more consistently and

Address for reprints:

Peter H. Jones, M.D.

Associate Professor

Baylor College of Medicine

Alkek Tower, ALKT A656

Houston, TX 77030, USA

e-mail: jones@bcm.tmc.edu dramatically than other lipid-lowering agents, thus exerting a significant impact on CHD risk. ${ }^{1-6}$

While these drugs have similar lipid-lowering effects, they vary in their derivation, pharmacology, and pharmacokinetics. The older statins (lovastatin, pravastatin, and simvastatin) are naturally derived, while the newer ones (atorvastatin, rosuvastatin, and itavastatin) are synthetic. In addition, several statin drugs are metabolized via the cytochrome P-450 (CYP) 3A4 enzyme system, a characteristic with potential clinical importance for drug interactions. ${ }^{7}$

As data from different statin trials continue to accumulate, more distinct features of the class and of the individual drugs within it will emerge. A review of observations to date about statin pharmacology, effects on lipid and nonlipid (pleiotropic) parameters, impact on clinical end points, and tolerability (in mono- and combination therapy) will lay the groundwork for future studies that may demonstrate more striking clinical differences among these drugs.

\section{Pharmacology}

Introduced in 1987, lovastatin was the first HMG-CoA reductase inhibitor-a natural product isolated from fungal metabolites. A similar agent, pravastatin, followed in 1991, along with simvastatin, a semisynthetic compound consisting of lovastatin plus an extra methyl group. Fluvastatin, cerivastatin, and atorvastatin are synthetic enantiomers, as is the investigational HMG-CoA reductase inhibitor rosuvastatin., 89

Both lovastatin and simvastatin have a closed lactone ring, which makes them prodrugs; these compounds must be converted in the liver to the open lactone form. All the other statins are open lactone forms. Each of the agents in this class has a characteristic pharmacophore group that interacts with the binding site of HMG-CoA reductase. ${ }^{10}$

The pharmacokinetic and pharmacodynamic characteristics of the various statins are summarized in Table I. Lovastatin, simvastatin, fluvastatin, atorvastatin, and cerivastatin are lipophilic agents, whereas pravastatin and rosuvastatin are hydrophilic, with negative values on a log-dose scale at $\mathrm{pH} 7.4$, compared with $>1$ for the other drugs. ${ }^{9}$ Half-lives are generally in the range of 1 to $3 \mathrm{~h}$, with the exception of atorvastatin (14 h) and rosuvastatin $(20 \mathrm{~h}){ }^{7,11}$ Lovastatin, simvastatin, and atorvastatin are metabolized by the most common isoform of the 
TABLE I Pharmacokinetic/pharmacodynamic comparison of statins

\begin{tabular}{lcccc}
\hline Statin & $\begin{array}{c}\text { Lipophilic/ } \\
\text { hydrophilic }\end{array}$ & $\begin{array}{c}\mathrm{T}_{1}^{1} / 2 \\
(\mathrm{~h})\end{array}$ & $\begin{array}{c}\text { Active } \\
\text { metabolites }\end{array}$ & Metabolism \\
\hline Lovastatin & Lipophilic & $2-3$ & Yes & CYP3A4 \\
Simvastatin & Lipophilic & 2 & Yes & CYP3A4 \\
Pravastatin & Hydrophilic & $1.5-2$ & No & No CYP \\
Fluvastatin & Lipophilic & 1 & No & CYP2C9 \\
Atorvastatin & Lipophilic & 14 & Yes & CYP3A4 \\
Rosuvastatin & Hydrophilic & 20 & Yes & CYP2C9, CYP2C19 \\
\hline
\end{tabular}

cytochrome P-450 system, namely CYP 3A4. Fluvastatin and rosuvastatin are primarily metabolized by $\mathrm{CYP} 2 \mathrm{C} 9$ and also, in the case of the latter agent, by CYP 2C19. Rosuvastatin does not undergo any appreciable metabolism by cytochrome P-450 $3 \mathrm{~A} 4$; thus, this agent presents less potential for drug-drug interactions than some other statins. 7,12

\section{Effects on Lipids}

The multicenter, randomized, open-label CURVES study compared the effects of five different statins on LDL cholesterol levels in 534 patients. ${ }^{13}$ Dose-dependent reductions in LDL cholesterol were significantly greater with atorvastatin than with milligram-equivalent doses of lovastatin, simvastatin, pravastatin, or fluvastatin (Fig. 1). Over the dose range of 10 to $80 \mathrm{mg}$, atorvastatin reduced LDL cholesterol by 38 to $54 \%$. Agents with even greater lipid-lowering effects have been under investigation. In a two-phase investigation involving 206 patients with hypercholesterolemia, rosuvastatin produced highly significant, dose-dependent reductions in LDL

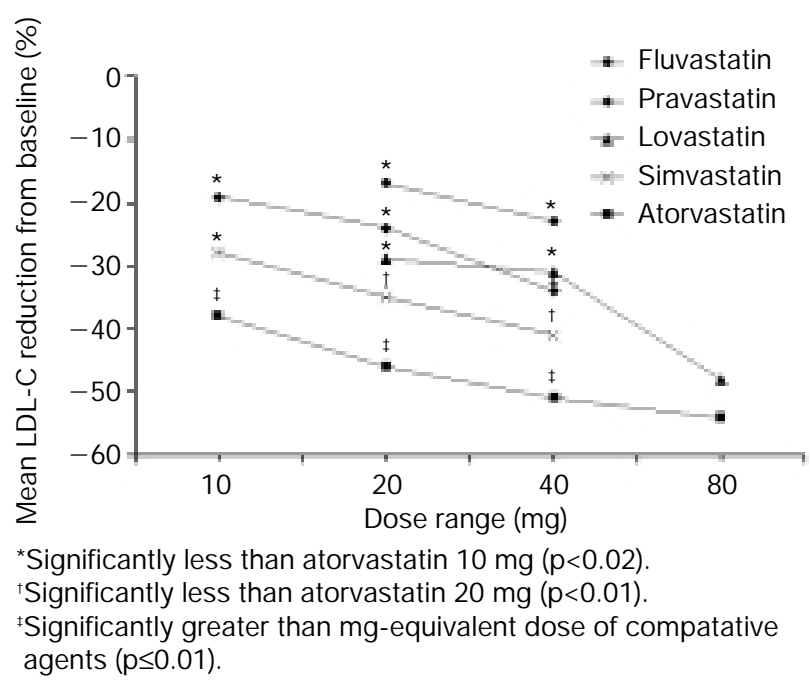

FIG. 1 Reductions in low-density lipoprotein cholesterol (LDL-C) with statins in the CURVES study. Reproduced from Ref. No. 13 with permission. cholesterol when compared with placebo; atorvastatin was used as a benchmark comparator. ${ }^{14}$

A more recent 12-week, multicenter, randomized, doubleblind, placebo-controlled trial found that reductions in LDL were significantly greater with rosuvastatin than with atorvastatin (Fig. 2). ${ }^{15}$ This comparison of the two agents in 516 patients with hypercholesterolemia revealed LDL reductions of 40 and $43 \%$ with rosuvastatin $5 \mathrm{mg}$ and $10 \mathrm{mg}$, respectively, as opposed to $35 \%$ with atorvastatin $10 \mathrm{mg}$ ( $\mathrm{p}<0.01$ vs. rosuvastatin $5 \mathrm{mg}, \mathrm{p}<0.05 \mathrm{vs}$. rosuvastatin $10 \mathrm{mg}$ ).

Another recent randomized, double-blind trial in 502 patients found significantly greater reductions in LDL cholesterol with rosuvastatin as opposed to pravastatin or simvastatin. ${ }^{16}$ At 12 weeks, rosuvastatin 5 and $10 \mathrm{mg}$ had reduced LDL cholesterol by 42 and $49 \%$, respectively, compared with $28 \%$ for pravastatin $20 \mathrm{mg}$ ( $\mathrm{p}<0.01$ vs. both rosuvastatin doses) and $37 \%$ for simvastatin ( $p<0.01$ vs. rosuvastatin 5 $\mathrm{mg}, \mathrm{p}<0.001 \mathrm{vs}$. rosuvastatin $10 \mathrm{mg}$ ).

In the CURVES study, the 40-mg dose of atorvastatin produced a greater reduction in triglyceride levels than did the 40mg dose of fluvastatin, lovastatin, pravastatin, and simvastatin; other doses did not produce different effects among the statins for triglycerides. ${ }^{13}$ Elsewhere, rosuvastatin also has been shown to produce significant reductions in triglyceride levels, albeit not in a dose-related manner. ${ }^{14}$

A large body of data gathered over the past decade has confirmed the significant inverse relationship between high-density lipoprotein (HDL) cholesterol levels and the risk of CHD events, ${ }^{17,18}$ but the potential impact of statins on HDL remains only partially understood. In a recent review, researchers suggested several possible mechanisms for this effect. ${ }^{19}$ Statins might bring about an increase in the messenger RNA (mRNA) for apolipoprotein A-I (apoA-I) at the promoter site. The elevation in mRNA for apoA-I appears to be reversed by adding mevalonate, suggesting an underlying process related to prenylated proteins or isoprenoids. Alternatively, statins may increase apoA-I expression by inhibiting Rho activation. Reduced Rho stimulates peroxisome proliferator activated receptor- $\alpha(\operatorname{PPAR} \alpha)$, which in turn is known to increase apoA-I expression, as shown in studies of fibrates. Furthermore,

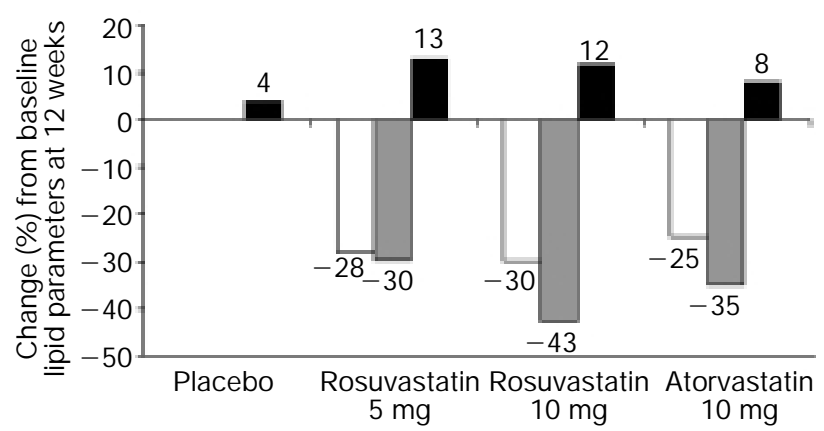

FIG. 2 Reductions in low-density lipoprotein cholesterol (LDL-C) and increases in high-density lipoprotein cholesterol (HDL-C) with rosuvastatin versus atorvastatin. $\square=$ Total cholesteral, $\square=$ LDL-C, $\mathbf{\square}=$ HDL-C. Data from Ref. No. 15. 
statins may reduce the activity of cholesterol ester transfer protein (CETP) to varying degrees, depending on the agent. Higher doses of atorvastatin may not inhibit CETP activity as strongly as some of the other statins, although data on CETP inhibition are contradictory. ${ }^{20}$ The extent to which any or all of these mechanisms contribute to increases in HDL cholesterol levels is far from clear, but all the statins could potentially display such actions.

Increases in HDL cholesterol levels ranged from 3.0 to $9.9 \%$ with the statins evaluated in the CURVES study. ${ }^{13}$ The amount of the increase did not differ significantly between atorvastatin and the other agents except at a dose of $40 \mathrm{mg}$, when elevations in HDL cholesterol were significantly greater with simvastatin than with atorvastatin $(\mathrm{p} \leq 0.05)$. In a recent study of rosuvastatin, HDL cholesterol levels increased by 10.0 to $14.4 \%$ over baseline in the same dosage range used in the CURVES study. ${ }^{14}$ Levels of HDL cholesterol also increased more with rosuvastatin at a dosage of $5 \mathrm{mg}$ or $10 \mathrm{mg}$ than with atorvastatin $10 \mathrm{mg}$ in a recent 12-week trial. With rosuvastatin $5 \mathrm{mg}$ and $10 \mathrm{mg}$, HDL levels rose $13 \%(\mathrm{p}<0.01)$ and $12 \%(\mathrm{p}<0.05)$ over baseline, respectively, vs. $8 \%$ with atorvastatin. ${ }^{15}$

The CURVES investigators are planning to repeat the protocol, using a larger number of patients and including rosuvastatin as one of the treatment arms in the Statin Therapies for Elevated Lipid Levels Compared Across Dose Ranges to Rosuvastatin (STELLAR) study. More than 2,000 patients will be randomized to 6 weeks of treatment with either rosuvastatin, simvastatin, or atorvastatin (each in doses of 10, 20, 40 , or $80 \mathrm{mg}$ ) or pravastatin $(10,20$, or $40 \mathrm{mg})$. The primary end point will be the percentage reduction in LDL cholesterol levels, secondary end points will include changes in other lipoprotein levels, and safety will be assessed with careful attention to adverse events. In a trial extension, all patients who are not initially randomized to rosuvastatin will receive rosuvastatin $10 \mathrm{mg}$ for at least 12 weeks.

\section{Effects on Clinical End Points}

Five major trials ${ }^{2-6}$ have confirmed that therapy with lovastatin, simvastatin, or pravastatin has beneficial effects on hard clinical end points in the primary and secondary prevention of CHD events. Pravastatin reduced rates of major coronary events (CHD death or nonfatal myocardial infarction) in highrisk patients with no evidence of $\mathrm{CHD}$ by $33 \%$, compared with placebo. ${ }^{6}$ Hypercholesterolemic patients with no history of CHD had $37 \%$ fewer CHD events (fatal or nonfatal myocardial infarction, unstable angina, or sudden cardiac death) with lovastatin therapy than with placebo. ${ }^{2}$ Among patients with established CHD, pravastatin and simvastatin reduced major coronary events by 23 to $34 \%$. $^{3-5}$

More recently, data from the Heart Protection Study ${ }^{21}$ suggested that statin therapy lowers CHD death rates among patients with average or below-average lipid levels who are still at increased risk because of previous myocardial infarction, noncardiac occlusive arterial disease, treated hypertension, or diabetes. Across all these patient groups, the rate of $\mathrm{CHD}$ events was $24 \%$ lower among patients taking simvastatin 40 $\mathrm{mg}$ /day over the 5.5-year study period than among similar patients taking placebo. A benefit was seen regardless of baseline LDL level.

Other studies have suggested beneficial effects of statin therapy on surrogate end points, including markers of atherosclerotic regression or progression as assessed by quantitative coronary angiography ${ }^{22,23}$ or high-resolution ultrasound. ${ }^{24}$ As evidence mounts that other surrogate end points correlate with CHD events, it is likely that lipid-lowering therapy will be found to affect them.

For example, statin therapy is showing promise in patients with acute coronary syndrome (ACS). In the Myocardial Ischemia Reduction with Aggressive Cholesterol Lowering (MIRACL) study, recurrent ischemic events in the first 16 weeks were reduced significantly in patients with ACS treated with atorvastatin $80 \mathrm{mg} /$ day. ${ }^{25}$ In a recent study using data from the Swedish Register of Cardiac Intensive Care (RIKSHIA), early initiation of statin treatment was associated with reduced 1-year mortality in patients with acute myocardial infarction. $^{26}$

\section{Pleiotropic Effects}

The Heart Protection Study has added weight to the intriguing theory that the antiatherogenic effects of statin therapy extend beyond lipid lowering - that they are, in fact, pleiotropic. Basic research suggests that the statins may exert such nonlipid effects as modifying endothelial function, mediating inflammatory responses, promoting plaque stability, and inhibiting thrombus formation. ${ }^{20}$ Statins stabilize endothelial nitric oxide synthase (eNOS) mRNA and increase the release of nitric oxide from the endothelium. ${ }^{27}$ Notably, reduced stability of eNOS is the major factor contributing to endothelial dysfunction in cardiovascular disease states (including CHD, myocardial ischemia, cerebral ischemia, and diabetes). Statins also increase the number of endothelial progenitor cells and promote their function, resulting in angiogenesis through the protein kinase AKT/eNOS pathway. ${ }^{27}$ In addition, they arrest the creation of vascular cell adhesion molecules in endothelial cells and limit the formation of CD11b and CD18 on leukocytes. ${ }^{28,29}$ Other work has shown that statins reduce levels of plasminogen activator inhibitor-1 while increasing the production of tissue plasminogen activator in endothelial cells and lowering the expression of tissue factor. ${ }^{30,31}$

Several studies have examined the effect of statins on inflammation. The Cholesterol and Recurrent Events (CARE) trial involving patients who had suffered acute myocardial infarction found a significant association between levels of high-sensitive C-reactive protein (hs-CRP, a marker of inflammation and predictor of CHD risk) and subsequent risk in a placebo group. ${ }^{32}$ The Pravastatin Inflammation/CRP Evaluation, a large-scale, prospective, randomized trial, revealed that pravastatin reduced CRP levels significantly, by $17 \%$ at 24 weeks $(\mathrm{p}<0.001) .{ }^{33}$ An analysis of data from 5,742 patients 
in the Air Force/Texas Coronary Atherosclerosis Prevention Study recently demonstrated a significant $15 \%$ reduction of CRP levels by lovastatin. ${ }^{34}$ Another study of hypercholesterolemic patients without $\mathrm{CHD}$ showed that rates of coronary events increased significantly with increases in baseline levels of CRP, and that lovastatin significantly reduced CRP levels..$^{35}$ In addition, a recent short-term study found that hs-CRP levels were reduced by 15 to $25 \%$ when hyperlipidemic patients were treated with simvastatin, pravastatin, or atorvastatin. ${ }^{36}$

The statins also decrease levels of isoprenoid proteins (GGPP and FPP), which are important in cellular signaling, and they may reduce osteoclastic activity, with possible relevance in osteoporosis. Furthermore, the statins may reduce the formation of beta-amyloid deposits, thereby possibly decreasing the risk of dementia. In addition, these agents may reduce levels of reactive oxygen species (i.e., superoxide and hydroxyl radicals), exert anti-inflammatory activities that could reduce the risk of diabetes, and produce antithrombotic effects that could reduce the risk of deep vein thrombosis. ${ }^{37,38}$ More research is needed to clarify whether such effects may translate into additional clinical benefit beyond LDL reduction in patients treated with statins.

\section{Tolerability}

More than 25,000 patients received lovastatin, simvastatin, or pravastatin in the six major, large-scale clinical trials involving more than 50,000 patients with hypercholesterolemia. ${ }^{2-6}$, 39,40 No serious morbidity or mortality was observed during these trials, and there were few drug interactions. Subsequent work has also found no appreciable tolerability issues among patients taking atorvastatin or rosuvastatin. ${ }^{13,41}$

The withdrawal of cerivastatin from the U.S. market in 2001, however, because of reports of serious myopathy and rhabdomyolysis, prompted concerns regarding the statins as a drug class. Investigators first noted a possible increase in the risk of myotoxicity with combined statin-fibrate therapy in a 1990 report of 12 cases of myopathy or rhabdomyolysis among patients taking lovastatin plus gemfibrozil. ${ }^{42}$ Since then, reports of 52 deaths from rhabdomyolysis worldwide in patients taking cerivastatin led to its withdrawal. ${ }^{43}$ The increased risk of myotoxicity appears to be greater with cerivastatin rather than generally present with all statins; among the 416 U.S. cases of fatal or nonfatal statin-related rhabdomyolysis, 10 times as many were associated with cerivastatin as with other statins. ${ }^{44}$

A 1995 analysis of data from 516 patients yielded evidence that combined statin-fibrate therapy poses no excess risk of adverse effects on skeletal muscle. Only $1 \%$ of these patients had significant, drug-related increases in creatine kinase (CK), and only $1 \%$ had significant muscle pain requiring drug discontinuation. ${ }^{45}$ No cases of rhabdomyolysis were observed. More recently, a review of 36 clinical trials involving a total of 1,674 patients treated with statins plus fibrates found CK levels greater than 10 times the upper limit of normal in only $0.12 \%$ of patients and no cases of rhabdomyolysis. ${ }^{46}$ Most of the studies in this analysis, however, excluded patients with renal or hepatic impairment, both of which are suspected risk factors for statin-fibrate-associated myopathy. Other risk factors include advanced age, female gender, increased serum creatinine, high-dose statin therapy, use of gemfibrozil rather than another fibrate, hypothyroidism, and concomitant use of CYP3A4-inhibiting medications such as erythromycin and azole antifungal agents. ${ }^{46,47}$

Although postmarketing reports of adverse events have been very limited compared with the large number of persons taking approved statins, a clinical advisory was recently issued by the American College of Cardiology/American Heart Association/ National Heart, Lung, and Blood Institute to provide updated recommendations for the appropriate use of statins, including cautions, contraindications, and monitoring. ${ }^{48}$

The main points made in the statement are:

- There are no clinically important differences in the rate of fatal complications among patients taking atorvastatin, fluvastatin, lovastatin, pravastatin, or simvastatin

- Statin therapy appears to carry a small risk of myopathy. Since most cases occur in patients who are at risk for the condition, if statins are used with appropriate caution, the likelihood of developing clinically important myopathy is substantially reduced

- The combination of a statin plus nicotinic acid seems to carry a lower risk for myopathy than does a statin plus a fibrate

- Myopathy is more likely to occur at higher statin doses; thus, doses should not exceed those required to attain the ATP III goal of therapy

- All persons starting statin therapy should be instructed to report muscle discomfort or weakness or brown urine immediately, which should then prompt a CK measurement.

Early trials suggested a possible increase in cancer risk with statin therapy, but subsequent analyses have proved that concern unfounded. Data from 6,721 cancer-free patients $(>65$ years old) who were taking lipid-lowering drugs showed that patients treated with statins had a $28 \%$ lower risk of cancer after 2.7 years of follow-up than those treated with bile acid resins ${ }^{49}$ Likewise, the five major statin trials (involving 30,817 patients followed for 5 to 6 years), ${ }^{2-6}$ analyzed togeth$\mathrm{er}$, showed no increased risk of all cancers or site-specific cancers with the use of statin therapy over a 5-year period..$^{50}$

\section{Conclusion}

Clinical trials to date indicate that the derivation of a statin (i.e., natural or synthetic) has no bearing on clinical pharmacologic effects. More work is required to determine whether the relative hydrophilicity or lipophilicity of a compound may have a bearing on efficacy or tolerability. Metabolism through the CYP system may be important, as there appear to be rele- 
vant clinical differences in drug interactions with statins that are not metabolized by this cytochrome system.

The various statins differ somewhat with regard to their LDL cholesterol-lowering effects. Clinical trials show greater decreases in LDL cholesterol with atorvastatin or rosuvastatin than with other agents in this class. Notably, recent data suggest that the LDL cholesterol-lowering ability of rosuvastatin may be even greater than that of atorvastatin. To date, not all statins have been evaluated with regard to their effects on hard clinical end points (e.g., CHD event rates), but the body of evidence accumulated thus far suggests that all agents in this class will eventually prove to have significant benefits. With the exception of cerivastatin, the statins do not appear to differ with regard to overall tolerability or incidence of adverse effects. Pleiotropic effects are most likely a class effect, and future research promises to shed more light on the extent of these effects.

\section{References}

1. Executive summary of the third report of the National Cholesterol Education Program (NCEP) Expert Panel on Detection, Evaluation, and Treatment of High Blood Cholesterol in Adults (Adult Treatment Panel III). J Am Med Assoc 2001;235:2486-2497

2. Downs JR, Clearfield M, Weis S, Whitney E, Shapiro DR, Beere PA, Langendorfer A, Stein EA, Kruyer W, Gotto AM Jr: Primary prevention of acute coronary events with lovastatin in men and women with average cholesterol levels: Results of AFCAPS/ TexCAPS. Air Force/Texas Coronary Atherosclerosis Prevention Study. J Am Med Assoc 1998;279:1615-1622

3. Scandinavian Simvastatin Survival Study Group: Randomised trial of cholesterol lowering in 4444 patients with coronary heart disease: The Scandinavian Simvastatin Survival Study (4S). Lancet 1994;344:1383-1389

4. Long-Term Intervention with Pravastatin in Ischaemic Disease (LIPID) Study Group: Prevention of cardiovascular events and death with pravastatin in patients with coronary heart disease and a broad range of initial cholesterol levels. N Engl J Med 1998;339: 1349-1357

5. Sacks FM, Pfeffer MA, Moyé LA, Rouleau JL, Rutherford JD, Cole TG, Brown L, Warnica JW, Arnold JMO, Wun C, Davis BR, Braunwald E, for the Cholesterol and Recurrent Events Trial Investigators: The effect of pravastatin on coronary events after myocardial infarction in patients with average cholesterol levels. NEngl J Med 1996;335:1001-1009

6. Shepherd J, Cobbe SM, Ford I, Isles CG, Lorimer AR, MacFarlane PW, McKillop JH, Packard CJ: Prevention of coronary heart disease with pravastatin in men with hypercholesterolemia. $N$ Engl $J$ Med 1995;333:1301-1307

7. Knopp RH: Drug treatment of lipid disorders. N Engl J Med 1999; 341:498-511

8. Blumenthal RS: Statins: Effective antiatherosclerotic therapy. Am Heart J 2000;139:577-583

9. McTaggart F, Buckett L, Davidson R, Holdgate G, McCormick A, Schneck D, Smith G, Warwick M: Preclinical and clinical pharmacology of rosuvastatin, a new 3-hydroxy-3-methylglutaryl coenzyme A reductase inhibitor. Am J Cardiol 2001;87(suppl):28B-32B

10. Istvan ES, Deisenhofer J: Structural mechanism for statin inhibition of HMG-CoA reductase. Science 2001;292:1160-1164

11. Hanefeld M: Clinical rationale for rosuvastatin, a potent new HMG-CoA reductase inhibitor. Int J Clin Pract 2001;55:399-405

12. McCormick AD, McKillop D, Bulters CJ, Miles GS, Baba T, Touchi A, Yamaguchi Y: ZD4522: An HMG-CoA reductase inhibitor free of metabolically mediated drug interactions: Metabolic studies in human in vitro systems (abstr 46). J Clin Pharmacol 2000; $40: 1055$

13. Jones P, Kafonek S, Laurora I, Hunninghake D: Comparative dose efficacy study of atorvastatin versus simvastatin, pravastatin, lovastatin, and fluvastatin in patients with hypercholesterolemia (the CURVES study). Am J Cardiol 1998;81:582-587

14. Olsson AG, Pears J, McKellar J, Mizan J, Raza A: Effect of rosuvastatin on low-density lipoprotein cholesterol in patients with hypercholesterolemia. Am J Cardiol 2001;88:504-508

15. Davidson M, Ma P, Stein EA, Gotto AM Jr, Raza A, Chitra R, Hutchinson H: Comparison of effects on low-density lipoprotein cholesterol and high-density lipoprotein cholesterol with rosuvastatin versus atorvastatin in patients with type IIa or IIb hypercholesterolemia. Am J Cardiol 2002;89:268-275

16. Paoletti R, Fahmy M, Mahla G, Mizan J, Southworth H: Rosuvastatin demonstrates greater reduction of low-density lipoprotein cholesterol compared with pravastatin and simvastatin in hypercholesterolaemic patients: A randomized, double-blind study. J Cardiovasc Risk 2001:8:383-390

17. Gordon DJ, Probstfield JL, Garrison RJ, Neaton JD, Castelli WP, Knoke JD, Jacobs DR Jr, Bangdiwala S, Tyroler HA: High-density lipoprotein cholesterol and cardiovascular disease. Four prospective American studies. Circulation 1989;79:8-15

18. Jacobs DR, Mebane IL, Bangdiwala SI, Criqui MH, Tyroler HA: High-density lipoprotein cholesterol as a predictor of cardiovascular disease mortality in men and women: The follow-up study of the Lipid Research Clinics Prevalence Study. Am J Epidemiol 1990; 131:32-47

19. Yamamoto Y, Gaynor RB: Therapeutic potential of inhibition of the $\mathrm{NF}-\kappa \mathrm{B}$ pathway in the treatment of inflammation and cancer. JClin Invest 2001;107:135-142

20. Rosenson RS, Tangney CC: Antiatherothrombotic properties of statins: Implications for cardiovascular event reduction. J Am Med Assoc 1998;279:1643-1650

21. MRC/BHF Heart Protection Study of cholesterol lowering with simvastatin in 20,536 high-risk individuals: A randomised placebocontrolled trial. Lancet 2002;360:7-22

22. Brown G, Albers JJ, Fisher LD, Schaefer SM, Lin JT, Kaplan C, Zhao XQ, Bisson BD, Fitzpatrick VF, Dodge HT: Regression of coronary artery disease as a result of intensive lipid lowering therapy in men with high levels of apolipoprotein B. N Engl J Med 1990;323:1289-1298

23. Effect of simvastatin on coronary atheroma: The Multicentre AntiAtheroma Study (MAAS). Lancet 1994;344:633-638

24. Smilde TJ, van den Berkmortel FW, Wollersheim H, van Langem $\mathrm{H}$, Kastelein JJ, Stalenhoef AF: The effect of cholesterol lowering on carotid and femoral artery wall stiffness and thickness in patients with familial hypercholesterolaemia. Eur J Clin Invest 2000;30: 473-480

25. Schwartz GG, Olsson AG, Ezekowitz MD, Ganz P, Oliver MF, Waters D, Zeiher A, Chaitman BR, Leslie S, Stern T: Effects of atorvastatin on early recurrent ischemic events in acute coronary syndromes: The MIRACL study: A randomized controlled trial. JAm Med Assoc 2001;285:1711-1718

26. Stenestrand U, Wallentin L: Early statin treatment following acute myocardial infarction and 1-year survival. J Am Med Assoc 2001;285:430-436

27. Lefer AM, Scalia R, Lefer DJ: Vascular effects of HMG CoA-reductase inhibitors (statins) unrelated to cholesterol lowering: New concepts for cardiovascular disease. Cardiovasc Res 2001;49: 281-287

28. Kwak BR, Mach F: Statins inhibit leukocyte recruitment. New evidence for their anti-inflammatory properties. Arterioscler Thromb Vasc Biol 2001;21:1712-1719

29. Takemoto M, Liao JK: Pleitropic effects of 3-hydroxy-3-methylglutaryl coenzyme A reductase inhibitors. Arterioscler Thromb Vasc Biol 2001;161:1405-1410

30. Bellosta S, Bernini F, Ferri N, Quarato P, Canavesi M, Arnaboldi L, Fumagalli R, Paoletti R, Corsini A: Direct vascular effects of 
HMG-CoA reductase inhibitors. Atherosclerosis 1998;137(suppl): S101-S109

31. Miller SJ: Emerging mechanisms for secondary cardioprotective effects of statins. Cardiovasc Res 2001;52:5-7

32. Ridker PM, Rifai N, Pfeffer MA, Sacks FM, Moyé LA, Goldman S, Flaker GC, Braunwald E: Inflammation, pravastatin, and the risk of coronary events after myocardial infarction in patients with average cholesterol levels. Cholesterol and Recurrent Events (CARE) Investigators. Circulation 1998;98:839-844

33. Albert MA, Danielson E, Rifai N, Ridker PM, for the PRINCE Investigators: Effect of statin therapy on C-reactive protein levels. The Pravastatin Inflammation/CRP Evaluation (PRINCE): A randomized trial and cohort study. J Am Med Assoc 2001;286:64-70

34. Ridker PM, Rifai N, Clearfield M, Downs JR, Weis SE, Miles JS, Gotto AM Jr, for the Air Force/Texas Coronary Atherosclerosis Prevention Study Investigators: Measurement of C-reactive protein for the targeting of statin therapy in the primary prevention of acute coronary events. N Engl J Med 2001;344:1959-1965

35. Ridker PM: High-sensitivity C-reactive protein: Potential adjunct for global risk assessment in the primary prevention of cardiovascular disease. Circulation 2001;103:1813-1818

36. Jialal I, Stein D, Balis D, Grundy SM, Adams-Huet B, Devarag S: Effect of hydroxymethyl glutaryl coenzyme A reductase inhibitor therapy on high sensitive C-reactive protein levels. Circulation 2001;103:1933-1935

37. Ray JG, Mamdani M, Tsuyuki RT, Anderson DR, Yeo EL, Laupacis A: Use of statins and the subsequent development of deep vein thrombosis. Arch Intern Med 2001;161:1405-1410

38. Freeman DJ, Norrie J, Sattar N, Neely RD, Cobbe SM, Ford I, Isles C, Lorimer AR, Macfarlane PW, McKillop JH, Packard CJ, Shepherd J, Gaw A: Pravastatin and the development of diabetes mellitus: Evidence for a protective treatment effect in the West of Scotland Coronary Prevention Study. Circulation 2001;103:357-362
39. Bradford RH, Shear CL, Chremos AN, Dujovne C, Downton M, Franklin FA, Gould AL, Heeney M, Higgins J, Hurley DP, Langendorfer A, Nash DT, Pool JL, Schnaper H: Expanded clinical evaluation of lovastatin (EXCEL) study results: I. Efficacy in modifying plasma lipoproteins and adverse event profile in 8,245 patients with moderate hypercholesterolemia. Ann Intern Med 1991;151:43-49

40. Collins R, Peto R, Armitage J: The MRC/BHF Heart Protection Study: Preliminary results. Int J Clin Pract 2002;56(1):53-56

41. Shepherd J, Hunninghake D, Harris S, Hutchinson H, Pears J: A review of the safety profile of rosuvastatin in an international phase II/III clinical trial programme. Int J Clin Pract 2002;124(suppl):15

42. Pierce LR, Wysowski DK, Gross TP: Myopathy and rhabdomyolysis associated with lovastatin-gemfibrozil combination therapy. J Am Med Assoc 1990;264:71-75

43. Wooltorton E: Bayer pulls cerivastatin (Baycol) from market. Can Med Assoc J 2001; 165:632

44. Furberg CD, Pitt B: Withdrawal of cerivastatin from the world market. Curr Control Trials Cardiovasc Med 2001;2:205-207

45. Shepherd J: Fibrates and statins in the treatment of hyperlipidaemia: An appraisal of their efficacy and safety. Eur Heart J 1995;16:5-13

46. Shek A, Ferrill MJ: Statin-fibrate combination therapy. Ann Pharmacother 2001;35:908-917

47. Milionis HJ, Tsapoga TG, Elisaf MS: Another report of acute rhabdomyolysis following cerivastatin monotherapy. Arch Intern Med 2001;161:2629-2930

48. Pasternak RC, Smith SC Jr, Bairey-Merz CN, Grundy SM, Cleeman JI, Lenfant C: ACC/AHA/NHLBI clinical advisory on the use and safety of statins. J Am Coll Cardiol 2002;40:567-572

49. Blais L, Desgagne A, LeLorier J: 3-Hydroxy-3-methylglutaryl coenzyme A reductase inhibitors and the risk of cancer: A nested case-control study. Arch Intern Med 2000;160:2363-2368

50. Bjerre LM, LeLorier J: Do statins cause cancer? A meta-analysis of large randomized clinical trials. Am J Med 2001;110:716-723 